\title{
Surgical Treatment and Follow-Up of Pulmonary Hydatid Cyst
}

\author{
Adel K. Ayeda Emad Alshawafb \\ aDepartment of Surgery, Faculty of Medicine, Kuwait University and ${ }^{b}$ Chest Diseases Hospital, Kuwait
}

\section{Key Words}

Hydatid cysts · Lung · Echinococcosis - Cystotomy · Capitonnage

\begin{abstract}
Objective: To report our experience of surgical procedures in the management of hydatid cysts of the lung and to assess the effect of postoperative chemotherapy. Subjects and Methods: In a longitudinal cohort study, 64 consecutive patients who presented with hydatid cysts of the lung from 1994 to 1998 were included. The main measures were: characteristics on presentation, operative techniques, postoperative morbidity, and the outcome of treatment. The mean age was 28 years (range 4-65 years). The most common symptoms were cough, chest pain, fever, and hemoptysis. Chest radiographs and computed tomograms were the main method of diagnosis. Pulmonary cystotomy and capitonnage were performed in 46 patients. Pulmonary resection was needed in 8 of 64 patients. Simultaneous combined resection of hydatid cysts through thoracotomy with transdiaphragmatic removal of liver cysts was performed in one stage in 13 patients. Results: Chest radiographs and CT scans showed a smoothly outlined spherical opacity in 45 patients. Other radiographic findings included ill-defined shadow (in 8 patients), pleural effusion (7 patients), air fluid level (3 patients), and hydropneumothorax in a single patient. There were $8(12.5 \%)$
\end{abstract}

cases of immediate postoperative complications. These occurred mostly in patients who had cysts larger than $10 \mathrm{~cm}(p=0.003)$. Thirty-four patients were treated by a 3-month course of albendazole chemotherapy. Four patients (6\%) had recurrences of the disease during the follow-up period. These recurrences occurred in patients with large cysts $>10 \mathrm{~cm}(p=0.001)$. Conclusion: Conservative surgical methods are the preferred surgical techniques. Postoperative chemotherapy with albendazole for 3 months is recommended.

Copyright $\odot 2003$ S. Karger AG, Basel

\section{Introduction}

Hydatid disease is generally a benign condition but it may behave like a malignancy when it metastasizes to lungs or other organs. It is caused by Echinococcus granulosus and is prevalent in sheep- and cattle-raising areas in the Mediterranean countries, Middle East, New Zealand, South America, and Australia [1,2]. Surgery is the treatment of choice for pulmonary hydatid cysts. Most authors advocate conservative lung resection with reservation of anatomical resection for cysts that have caused destruction of lung parenchyma [1-3]. Chemotherapy has been suggested for postoperative management to prevent secondary recurrence of the disease [3-6]. We report a consecutive series of 64 patients presenting with hydatid cysts between 1994 and 1998 to review our experience of surgi-

\section{KARGER \\ Fax +41613061234 \\ E-Mail karger@karger.ch \\ www. karger.com

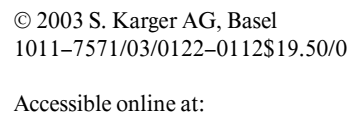

Dr. Adel K. Ayed, Associate Professor

Department of Surgery, Faculty of Medicine

Kuwait University, PO Box 24923

13110 Safat (Kuwait)

Tel. +965 5319475, Fax +965 5319597, E-Mail Adel@hsc.kuniv.edu.kw 
cal techniques in the treatment of hydatid cysts of the lung, and to assess the utility of postoperative chemotherapy.

\section{Subjects and Methods}

The study was conducted at the Chest Diseases Hospital in Kuwait, which is the only center for the surgical treatment of chest disorders in Kuwait. From 1994 to 1998, 64 patients were included in the study. Thirty-eight patients were males and 26 were females. The ages ranged from 4-65 years (mean 28).

\section{Presentation}

The various symptoms experienced by the patients included cough $(n=41)$, chest pain $(n=26)$, fever $(n=7)$, and hemoptysis $(n=$ 5). Twelve patients were asymptomatic. Allergic reactions were not observed in any patient. Hydatoptysis was observed in 2 patients. All patients underwent an immunologic test (indirect hemagglutination test) with positive results in $41(64 \%)$ patients.

\section{Surgical Techniques}

All patients were treated surgically, using a posterolateral thoracotomy approach. Six patients with bilateral disease were managed with staged bilateral thoracotomies. A total of 80 procedures were performed on the 64 patients. Table 1 shows the operative methods used. Cystotomy, bronchial suture and capitonnage were carried out in $46(57.5 \%)$ patients. The thoracotomy wound and the lung except for the area containing the cyst were covered with gauze moistened with hypertonic saline to prevent implantation of scolices or daughter cysts. A large needle connected to a suction tip was inserted into the cyst to aspirate the cystic material. The cyst was then opened and the tip of a large suction tube was introduced immediately to evacuate the endocyst and the hydatid membranes. The cavity was irrigated with hypertonic saline, and the bronchial openings sutured with $3 / 0$ polygalactin 910 (Vicryl) sutures.

Imbricating sutures from within were used for obliteration of the cavity (capitonnage). Two patients had thickened pleura and underwent decortication to facilitate expansion of the lung. In 11 patients, the cyst was removed intact with surrounding healthy parenchyma by wedge resection with an automatic stapling device (Auto-suture GIA, Norwalk, Conn., USA). More radical procedures, such as lobectomy, were performed in 8 patients $(10 \%)$ because chronic inflammation and bronchiectatic changes were present in the whole lobe. Coexisting liver cysts were present the right lobe of the liver in 13 $(16 \%)$ patients and were managed through transdiaphragmatic approach. Cystotomy was performed in the conventional manner as described for the lung. The bile leak area was sutured with $4 / 0$ polygalactin 910 (Vicryl) sutures. The residual cavity was kept open and indwelling tube drainage was inserted subdiaphragmatically. The tube was removed after bile drainage ceased and complete closure of the residual cavity was then performed. The diaphragmatic opening was closed in two layers.

Thirty-four patients (regardless of size of the cyst) were treated postoperatively with a 3-month course of albendazole $(10 \mathrm{mg} / \mathrm{kg})$ daily by mouth in two doses. The follow-up period ranged from 2 to 4 years. At checkup examinations, clinical symptoms were noted and chest radiographs were taken.

Pulmonary Hydatid Disease
Table 1. Operative methods used in 64 patients $^{1}$

\begin{tabular}{lll}
\hline & \multicolumn{2}{l}{ Patients } \\
\cline { 2 - 3 } & $\mathrm{n}$ & $\%$ \\
\hline Cystotomy and capitonnage & 46 & 57.5 \\
Transdiaphragmatic liver cystotomy & 13 & 16 \\
Wedge resection & 11 & 14 \\
Lobectomy & 8 & 10 \\
Decortication & 2 & 2.5 \\
\hline
\end{tabular}

1 Two-stage thoracotomy was performed in 6 patients with bilateral pulmonary hydatid cysts.

\section{Statistical Analysis}

SPSS software (window version 8) was used to process the data. The cutoff level for statistical significance was $p<0.05$. The Pearson chi-square test was used to ascertain the significance of association between two categorical variables. The chi-square test was replaced by the Fisher's exact test of the cell frequencies of any of the $2 \times 2$ contingency tables below five.

\section{Results}

\section{Radiologic Findings}

The most common finding on the chest X-ray film was a smoothly outlined, dense spherical opacity (fig. 1). The radiologic findings are summarized in table 2 . The most frequent location for extrapulmonary cysts in these 64 patients was the liver $(n=13)$. Other locations included spleen $(n=2)$, heart $(n=1)$ and kidney $(n=1)$. The cysts were located in the right lung in $46(72 \%)$ patients, in the left lung in $24(37 \%)$, and in both lungs in $6(9 \%)$. Multiple pulmonary cysts were found in $9(14 \%)$ patients. Giant pulmonary cysts $(>10 \mathrm{~cm}$ in size) were seen in 19 cases $(30 \%)$.

\section{Outcome of Surgery}

The most common complication in the early postoperative period was prolonged air leak ( $>5$ days) in $4(6 \%)$ patients. Three of these patients were treated successfully by tube drainage. The remaining patient underwent reoperation and right lower lobectomy. Other complications included pleural effusion, in 3 patients, and wound infection in 1 . Complications occurred in $6 / 19$ patients with large cysts $>10 \mathrm{~cm}$ and $2 / 45$ patients with smaller cysts. The difference was statistically significant $(p=0.0003)$. There was no correlation between the type of operation and postoperative complications $(p=0.4)$. One patient in 


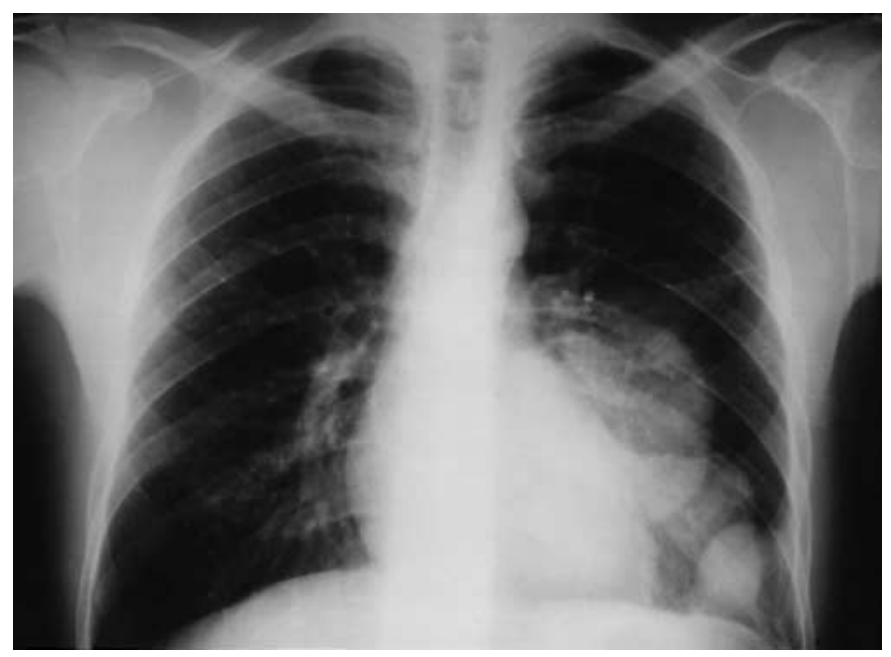

Fig. 1. Posteroanterior chest radiograph of a patient with multiple hydatid cysts of the left lung.

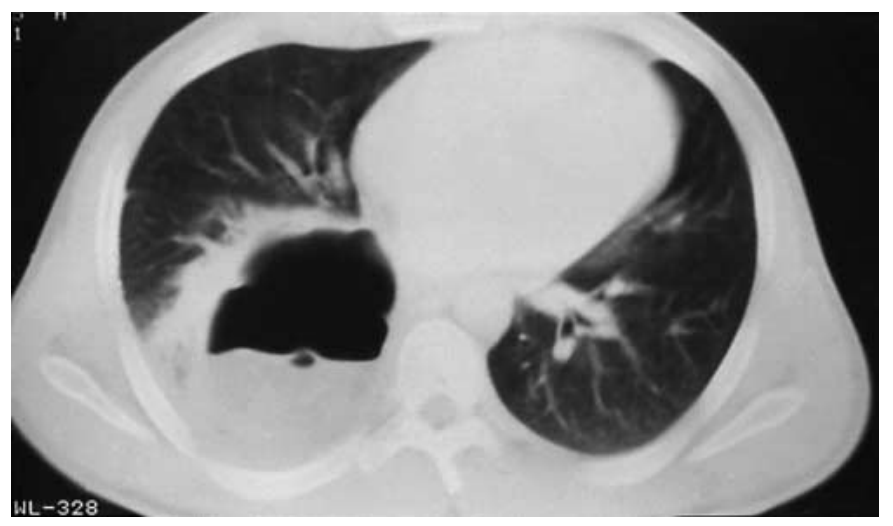

Fig. 2. CT. Hydatid cyst of the right lung.

Table 2. Radiologic findings of 64 cases of hydatid cysts

\begin{tabular}{lrr}
\hline & \multicolumn{2}{l}{ Patients } \\
\cline { 2 - 3 } & $\mathrm{n}$ & $\%$ \\
\hline Smooth spherical opacity & 45 & 70 \\
Ill-defined lung shadow & 8 & 12 \\
Pleural effusion & 7 & 11 \\
Air fluid level & 3 & 5 \\
Hydropneumothorax & 1 & 2 \\
\hline
\end{tabular}

this series died because of pulmonary embolism. The mean hospital stay was 9 days (range 7-16).

Follow-Up. Recurrence was observed in $4(21 \%)$ patients with a large cyst $>10 \mathrm{~cm}$ and no recurrence was observed in patients treated for small cysts. The difference was statistically significant $(p<0.001)$. The 4 recurrences occurred after cystotomy and capitonnage.

Recurrences occurred in 3/30 patients who did not receive postoperative chemotherapy, and in 1 of the 34 who received postoperative chemotherapy. This difference in recurrence rates was not significant $(p=0.24)$. All recurrences occurred in the operative site, 1 year after the operation, and all were treated with a second thoracotomy.

\section{Discussion}

Echinococcosis is a parasitic disease frequently seen in sheep- and cattle-raising countries and is encountered in the Middle East region. Diagnostic difficulties were not experienced since the disease is common in our country. Plain chest radiography and computed tomography (CT) are sufficient for diagnosis $[1,5,6]$. The most common feature noticed on plain chest radiographs was the presence of round, homogeneous, well-defined opacities as described in earlier reports $[2,7,8]$. CT scans show features of pulmonary hydatidosis $[8,9]$. An increase in the CT density of the lung mass and/or a thick cyst wall was the most prominent finding (fig. 2). Other notable features include a crescent-shaped rim of air at the lower end of the cyst (inverse crescent sign) and a pocket of air dissecting into the wall of the cyst, giving it the shape of a ring (signet ring sign) [9].

Surgery remains the primary treatment for most patients with hydatid disease. The aims of surgery for lung cysts are evacuation of the cyst, prevention of cyst rupture at the operative site and management of the residual cavity. The surgical findings determine the choice of an appropriate technique. Most authors advocate conservative lung resection, reserving lobectomy for cases where ruptured cysts have caused destruction or infection of the adjacent tissue $[1,10]$. Various conservative surgical techniques have been described in the literature: enucleation, wedge resection, cystotomy and capitonnage of the residual cavity, and segmentectomy [2, 11, 12]. In the present series, cystotomy and capitonnage of the residual cavity were the operative procedures applied most frequently. Enucleation of a large cyst should be avoided because it carries an increased risk of rupture during the separation 
of the pericystic zone from the laminated membrane [8]. Pulmonary cystotomy and capitonnage were used in $61.4 \%$ of patients by Burgos et al. [7], $84 \%$ of 1,055 patients by Dogan et al. [2], and in $71 \%$ in 67 cases reported by Karaoglanoglu et al. [3]. Saidi [13] recommended leaving the residual cavity open because the pulmonary parenchyma automatically obliterates the space and the surface of the lung at the site of the residual cavity will be covered by the pleura.

Lung resection was used only if parenchymal lesions appeared irreversible or when a complication such as bronchopleural fistula $[1,2]$ occurred after conservative treatment. In this study, the resection rate was $10 \%$, comparable to previous reports: $6 \%$ in giant hydatid cysts reported by Halezeroglu et al. [8], 12\% in 807 cases reported by Qian [14], 13\% in a giant hydatid cyst group and $9 \%$ in a nonselected group reported by Karaoglanoglu et al. [3], and $31 \%$ in 331 cases reported by Burgos et al. [7].

In 13 patients with a liver cyst or an extension of a liver cyst into the right hemithorax, the thoracic transdiaphragmatic approach was used for management. A conventional approach as described for the lung and tube drainage $[10,15]$ was used without any complications. Excision of liver cysts and primary closure of the residual cavity without drainage have been reported [2, 4].

A two-staged thoracotomy was used in 6 patients with bilateral hydatid cysts due to a large cyst size and posterior location. However, median sternotomy has become the preferred approach for bilateral hydatid cysts in recent years [4, 5, 16]. Dhaliwal and Kalkat [4] reported their experience with 5 patients with combined bilateral pulmonary and hepatic hydatid cysts in which simultaneous combined resection through midsternotomy along with laparotomy or transdiaphragmatic removal of cysts resulted in minimum morbidity and no recurrence. However, median sternotomy is considered unsuitable in the presence of pleural complications like empyema, massive infection with tissue destruction that require resection, and impaired general condition of the patient that would contraindicate extended surgical procedures [5].

Postoperative complications are influenced by the size of cysts, with complication rates reported between 12.9 and $19 \%$ in the literature $[1,3,8,17]$. Reports suggest a higher complication rate for groups treated by conservative surgery $[2,3]$. In this study, the complication rate was $12.5 \%$ and is seen more in patients with large cysts $(>10 \mathrm{~cm})$. However, no relationship was apparent between postoperative complications and the operative techniques used.
Postoperative chemotherapy has been used to prevent secondary recurrence in patients with pulmonary hydatid cysts $[3-6,18]$. In the present study, the recurrence rate was higher in the group in whom postoperative chemotherapy was not used. Although the difference was not statistically significant, we recommend postoperative chemotherapy for 3 months to prevent recurrence of disease from release of hydatid daughter cysts into the pleural space, particularly in cases of intraoperative spillage or when the presence of small undetected cysts is suspected [4].

Reported recurrence rates of hydatid lung cysts are low $[2,3,5]$. In this series 4 patients had a recurrence, of whom 3 had a ruptured cyst before the operation and 1 probably resulted from spillage of cyst contents into the thorax after needle aspiration. Athanassiadi et al. [10] reported 7/85 recurrences of the disease. Technical problems may increase the chance of inadvertent operative rupture and spillage of cyst contents leading to subsequent regrowth of the cysts. Protection of the operative field with hypertonic saline, gentle manipulation of the cysts, and irrigation of the pleural cavity with hypertonic saline should help to prevent recurrence of the disease.

\section{Conclusion}

Surgery should remain the primary treatment for pulmonary hydatid cysts. Conservative lung resection is appropriate for most patients. This study also emphasizes the one-stage surgical approach for lung and liver hydatid cysts. Protection of the operative field with hypertonic saline and gentle manipulations of the cysts are recommended, together with prophylactic postoperative chemotherapy, to prevent recurrence. 


\section{References}

1 Aytac A, Yurdakul Y, Ikizler C, Olga R, Saylam A: Pulmonary hydatid disease: Report of 100 patients. Ann Thorac Surg 1977;23:145151.

2 Dogan R, Yuksel M, Cetin G, Suzer K, Alp M, Suzer K, Alp M, Kaya S, Unlu M, Moldibi B: Surgical treatment of hydatid cysts of the lung: Report on 1055 patients. Thorax 1989;44:192199.

3 Karaoglanoglu N, Kurkcuoglu IC, Gorguner M, Eroglu A, Turkyilmaz A: Giant hydatid lung cysts. Eur J Cardiothorac Surg 2001;19: 914-917.

4 Dhaliwal RS, Kalkat MS: One-stage surgical procedure for bilateral lung and liver hydatid cysts. Ann Thorac Surg 1997;64:338-341.

5 Petrov DB, Terzinacheva PP, Djambazov VI, Plochev MP, Goranov EP, Minchev TR, Petrov PV: Surgical treatment of bilateral hydatid disease of the lung. Eur J Cardiothorac Surg 2001;19:918-923.

6 Topcu S, Kurul IC, Tastepe I, Bozkurt D, Gulhan E, Cetin G: Surgical treatment of pulmonary hydatid cysts in children. J Thorac Cardiovasc Surg 2000;120:1097-1101.
7 Burgos L, Baquerizo A, Munoz W, de Aretxabala X, Solar C, Fonseca L: Experience in the surgical treatment of 331 patients with hydatidosis. J Thorac Cardiovasc Surg 1991;102: 427-430.

8 Halezeroglu S, Celik M, Uysal A, Senol C, Keles M, Arman B: Giant hydatid cysts of the lung. J Thorac Cardiovasc Surg 1997;113:712717.

9 Koul PA, Koul AN, Wahid A, Mir FA: CT in pulmonary hydatid disease: Unusual appearance. Chest 2000;118:1645-1647.

10 Athanassiadi K, Kalavrouziotis G, Loutsidis A, Bellenis I, Exarchos N: Surgical treatment of echinococcosis by a transthoracic approach: A review of 85 cases. Eur J Cardiothorac Surg 1998;14:134-140.

11 Aarons BJ: Thoracic surgery for hydatid disease. World J Surg 1999;23:1105-1109.

12 Moore RD, Urschel JD, Fraser RE, Nakai SS, Geeraert AJ: Cystic hydatid lung disease in northwest Canada. Can J Surg 1994;37:20-22.
3 Saidi F: Surgery of Hydatid Disease. Philadelphia, Saunders, 1976, pp 156-281.

14 Qian ZX: Thoracic hydatid cysts: A report of 842 cases treated over a thirty-year period. Ann Thorac Surg 1988;46:342-346.

5 Peleg H, Best LA, Gaitini D: Simultaneous operation for hydatid cysts of right lung and liver. J Thorac Cardiovasc Surg 1985;90:783787.

16 Cetin G, Dogan R, Yuksel M, Alp M, Ucanok K, Kaya S, Unlu M: Surgical treatment of bilateral hydatid disease of the lung via median sternotomy: Experience in 60 consecutive patients. Thorac Cardiovasc Surg 1988;36:114-117.

17 Burgos R, Varela A, Castedo E, Roda J, Montero CG, Serrano S, Tellez G, Ugarte J: Pulmonary hydatidosis: Surgical treatment and follow-up of 240 cases. Eur J Cardiothorac Surg 1999; 16:628-635.

18 Gil-Grande LA, Rodriguez-Caabeiro F, Prieto JG, Sanchez-Ruano JJ, Brasa C, Aguilar L, Garcia-Hoz F, Casado N, Barcena R, Alvarez A: Randomized controlled trial of efficacy of albendazole in intra-abdominal hydatid disease. Lancet 1993;342:1269-1272. 